\title{
APROXIMACIÓN A LA PALEOPATOLOGÍA DE LA COLUMNA VERTEBRAL EN EL CEMENTERIO DE LA MISIÓN SALESIANA "NUESTRA SEÑORA DE LA CANDELARIA" (S. XIX-XX, RÍO GRANDE, ARGENTINA)
}

\author{
PALEOPATHOLOGY OF THE VERTEBRAL COLUMN AT THE CEMETERY OF \\ THE SALESIAN MISSION "NUESTRA SEÑORA DE LA CANDELARIA" (RÍO \\ GRANDE, ARGENTINA)
}

Luis Moreno Estefanel1, Manuel Domingo D'Angelo del Campo 1,2,3*, Manuel Campo Martín', Pamela García Laborde ${ }^{2,3,4}$, Óscar Cambra-Moo', Armando González Martín y y Ricardo A. Guichón ${ }^{2,3,4}$

\footnotetext{
${ }^{I}$ Laboratorio de Poblaciones de Pasado (LAPP). Departamento de Biología. Facultad de Ciencias. Universidad Autónoma de Madrid (UAM). Madrid. España

${ }^{2}$ Laboratorio de Ecología Evolutiva Humana (LEEH). Facultad de Ciencias Sociales (FACSO). Universidad del Centro de la Provincia de Buenos Aires (UNCPBA). Quequén. Argentina

${ }^{3}$ Núcleo de Estudios Interdisciplinarios de Poblaciones Humanas de Patagonia Austral (NEIPHPA). FACSO. UNCPBA. Quequén. Argentina

${ }^{4}$ Consejo Nacional de Investigaciones Científicas y Técnicas (CONICET). Argentina
}

\section{PALABRAS CLAVE espondiloartrosis; nódulos de Schmörl; vértebra; Tierra del Fuego}

RESUMEN Desde una perspectiva biológica, este trabajo pretende realizar un nuevo aporte sobre un momento histórico relevante, el contacto interétnico entre europeos y nativos en Tierra del Fuego, mediante el estudio de la columna vertebral de 16 individuos adultos procedentes del cementerio de la Misión Salesiana "Nuestra Señora de La Candelaria". La metodología utilizada recoge y analiza datos acerca del estado de preservación de la muestra, la presencia de nódulos de Schmörl y los signos artrósicos de las vértebras. Los patrones de distribución y las frecuencias de las lesiones observadas se sitúan dentro de los rangos registrados en otras regiones del mundo. Rev Arg Antrop Biol 20(2), 2018. doi:10.17139/ raab.2018.0020.02.06

\section{KEY WORDS spondyloarthrosis; Schmörl nodes; vertebrae; Tierra del Fuego}

ABSTRACT From a biological perspective, this study aims to make a new contribution on a relevant historical moment, European-native contact in Tierra del Fuego, through the analysis of the vertebral column of 16 adults from the cemetery of the Salesian Mission "Nuestra Señora de la Candelaria". The methodology used here

La Misión Salesiana "Nuestra Señora de La Candelaria” (MSLC), se establece en Río Grande (Argentina) en el año 1893 con el propósito de evangelizar a la población originaria. Durante el periodo en que la institución permaneció activa, habitaron en ella de manera permanente o estacional miembros de la comunidad Selk'nam (Casali, Fugassa, y Guichón, 2009). Pasaron de un estilo de vida cazador-recolector nómada con alta movilidad (Gusinde, [1931] 1982a, b; Chapman, 1977; Guichón, 1994) a una vida sedentaria con gran densidad poblacional e incluso cierto grado de hacinamiento (Casali, 2011). Esta situación, como relatan las fuentes históricas, implicó profundas transformaciones en la forma collects and analyzes data about the preservation state of the sample, presence of Schmörl nodes, and osteoarthritic signs. The frequency of lesions and the patterns observed fall within the ranges reported in other regions around the world. Rev Arg Antrop Biol 20(2), 2018. doi:10.17139/raab.2018.0020.02.06

Financiamiento: parcialmente financiado por el proyecto PICT 0575 (Agencia Nacional de Promoción Científica y Tecnológica. Ministerio de Ciencia, Tecnología e Innovación Productiva. Argentina).

\footnotetext{
*Correspondencia a: Manuel D. D’Angelo del Campo. Laboratorio de Ecología Evolutiva Humana, Núcleo de Estudios Interdisciplinarios de Poblaciones Humanas de Patagonia Austral. Facultad de Ciencias Sociales. Universidad del Centro de la Provincia de Buenos Aires. Calle 508 N $^{\circ}$ 881. CP 7631 Quequén. Buenos Aires. Argentina / Laboratorio de Poblaciones de Pasado, Departamento de Biología. Facultad de Ciencias. Universidad Autónoma de Madrid. C/Darwin 2, E-28049 Madrid. España. E-mail: manueldomingodangelo@gmail.com
}

Recibido 2 Octubre 2017; aceptado 22 Diciembre 2017

doi:10.17139/raab.2018.0020.02.06 
de vida local; cambios sociales con importantes repercusiones biológicas: modificaciones en los patrones dietarios, nuevas tareas productivas, etc. (Casali, 2011; García Laborde, Valenzuela y Guichón, 2014; Martucci, 2016). En lo que respecta a las patologías concernientes a este contexto, los trabajos realizados sobre fuentes históricas dan cuenta de alta frecuencia de enfermedades pulmonares tales como la "pulmonía", la tuberculosis o la "tos convulsa" (Guichón, Suby, Casali y Fugassa, 2006; Casali, 2011). Dado que aquellos que murieron en este entorno fueron inhumados en el cementerio misional, la MSLC supone una fuente de información relevante para profundizar en el conocimiento del contacto interpoblacional. Los estudios realizados sobre restos óseos exhumados del cementerio de la MSLC han señalado diferencias con respecto a individuos originarios recuperados en un contexto arqueológico no misional. Los problemas sistémicos producidos por estrés nutricional habrían estado presentes en ambos escenarios; sin embargo, dentro de la misión, el cambio en la dieta, el hacinamiento y las altas frecuencias de enfermedades infecciosas, actuando de manera sinérgica, habrían exacerbado dicho estrés, resultando en un aumento de estos indicadores (García Laborde, Suby, Guichón y Casali, 2010, García Laborde et al., 2014; García Laborde, 2017). De la misma manera, se observa un aumento en los casos de espondilólisis (D’Angelo del Campo, Suby, García-Laborde y Guichón, 2017). Teniendo en cuenta estos primeros hallazgos, y siendo la columna vertebral un elemento esquelético sensible a ser afectado por los procesos patológicos (Campo, 2003), el estudio desde el punto de vista paleopatológico de ésta, puede aportar nueva información acerca del momento de contacto, siendo el objeto de análisis de este trabajo.

A pesar de ser una estructura ósea susceptible de presentar lesiones con relativa frecuencia, los estudios que abordan los signos patológicos del esqueleto axial de manera específica en Patagonia Austral (PA) ${ }^{1}$ son escasos (Suby, 2014). Este hecho se debe a que los análisis paleopatológicos de los elementos vertebrales se suelen incluir en estudios que abordan la problemática de manera más generalista, esto es, atendiendo a todas las afecciones que puede presentar un sujeto, sin hacer énfasis en ningún elemento esquelético concreto (Alfonso-Durruty, Calás y Morello,
2011; Aspillaga, Ocampo y Rivas, 1999; Castro y Aspillaga, 1991; Constantinescu, 1997, 1999; Guichón y Suby, 2006, 2011; L'Hereux y Amorosi, 2009; L'Hereux y Barberena, 2008; Santiago, Salemme, Suby y Guichón, 2011; Suby y Guichón, 2010; Suby, Guichón y Senatore, 2009a; Suby, Guichón y Zangrando 2009b; Suby, Santiago y Salemme, 2008; Suby, Zangrando y Piana, 2011). Situación que se puede haber visto influenciada por las características del registro bioarquelógico de la región, caracterizado por hallazgos aislados con puntuales excepciones (Guichón, Barberena y Borrero, 2001; L'Heureux y Barberena, 2008; L'Heureux y Amorosi, 2009; L'Heureux y Amorosi, 2010; Santiago et al., 2011). No se han encontrado cementerios anteriores al contacto, aunque sí posteriores, asociados en todos los casos a misiones con fines evangelizadores, de las órdenes salesiana (Dawson y Río Grande) o anglicana (Ushuaia).

El esqueleto axial puede reflejar signos patológicos de carácter diverso. Los nódulos de Schmörl representan una lesión frecuente en los cuerpos vertebrales (Schmörl y Junghanns, 1959). Aparecen principalmente en la región dorsolumbar (Kyere et al., 2012) y se producen como consecuencia de una protrusión del disco intervertebral que afecta a la placa de cubierta o base de la vértebra adyacente (Real Academia Nacional de Medicina-RANM-, 2011). Se manifiestan en forma de hundimientos y surcos en la superficie de los platillos vertebrales, que pueden llegar a penetrar en el tejido esponjoso, resultando verdaderas hernias intraesponjosas (Campo, 2003). La etiología de estas lesiones es motivo de debate, existiendo distintas visiones. Dar et al. (2010) proponen su origen en una fase temprana del desarrollo del individuo, motivado por las tensiones torsionales a las que están sometidas estas vértebras. Burke (2012) relaciona la distribución de la patología con factores biomecánicos de la columna vertebral. La región torácica baja tiene una movilidad limitada, discos intervertebrales más finos y un elevado riesgo de lesión por estrés de torsión, lo que haría a esta zona propensa a desarrollar nódulos. Autores como Plomp, Roberts y Viðarsdóttir (2012) encuentran correlación entre los nódulos y la morfología (tamaño y forma) de las vértebras donde se desarrollan. Esta morfología podría predisponer al individuo a una inestabilidad biomecánica. Williams, 
Manek, Sambrook, Spector y MacGregor (2007) sostienen que los nódulos de Schmörl están fuertemente determinados genéticamente.

Por otro lado, las patologías de índole degenerativo, tales como las relacionadas con la artrosis u osteoartritis, están entre las más frecuentes del registro osteoarqueológico (Ortner, 2003; Weiss y Jurmain, 2007). Cuando la artrosis afecta a los elementos vertebrales se denomina espondiloartrosis, caracterizándose por una degeneración inicial del disco intervertebral, que puede acompañarse o no de protrusión discal y de reacción osteofítica marginal (RANM, 2011). La pérdida de altura del disco y la reiteración de movimientos anormales intersomáticos origina una modificación en la disposición normal de las carillas articulares de las articulaciones interapofisarias y consecuentemente, una sobrecarga funcional de las mismas, con aparición de fenómenos degenerativos (RANM, 2011). Actualmente se propone un origen multifactorial de la enfermedad, es decir, es posible que se trate de diferentes patologías que se expresen a través de una misma manifestación clínica y que provoquen las mismas lesiones en el esqueleto, debido a que el hueso tiene un margen de reacción limitado (Weiss y Jurmain, 2007). Las lesiones articulares asociadas a la espondiloartrosis incluyen osteofitos, labiación y eburnación (Rogers y Waldron, 1995).

A la hora de analizar restos osteoarqueológicos, el estado de preservación o alteración tafonómica afecta a aspectos tales como la representatividad de la muestra y la cantidad y calidad de los datos que se puedan analizar, lo que limita las conclusiones que puedan extraerse (Séguy y Buchet, 2011; Waldron, 1987). Como señalan Rascón, Cambra-Moo, Pimentel, González y Campo (2011), un buen estado de preservación facilita el diagnóstico paleopatológico, aunque no debe obviarse la información que pueden aportar aquellos restos óseos que se encuentren en peor estado de preservación, porque si bien la información aportada estará sesgada, sigue siendo relevante.

En el presente trabajo, se estudian los signos patológicos del esqueleto axial (espondiloartrosis y nódulos de Schmörl) de los individuos adultos exhumados del cementerio de la MSLC. El objetivo es profundizar en el conocimiento de los cambios que pudieron sufrir los sujetos que habitaron y murieron en esta institución. Para ello, se han analizado las vértebras desde el punto de vista paleopatológico, teniendo en cuenta que los restos óseos pertenecen a individuos acotados espacial y temporalmente, cuyo estilo de vida fue modificado por el contacto interétnico.

\section{MATERIAL Y MÉTODOS}

Se analizan columnas vertebrales de 16 individuos adultos exhumados del cementerio de la MSLC, el cual estuvo activo entre los años 1897 y 1948 (Casali, 2011) y dista $12 \mathrm{~km}$ al norte de la ciudad de Río Grande, Tierra del Fuego (TdF), Argentina (Fig. 1). Los 16 sujetos fueron inhumados en el sector sur del cementerio, superando

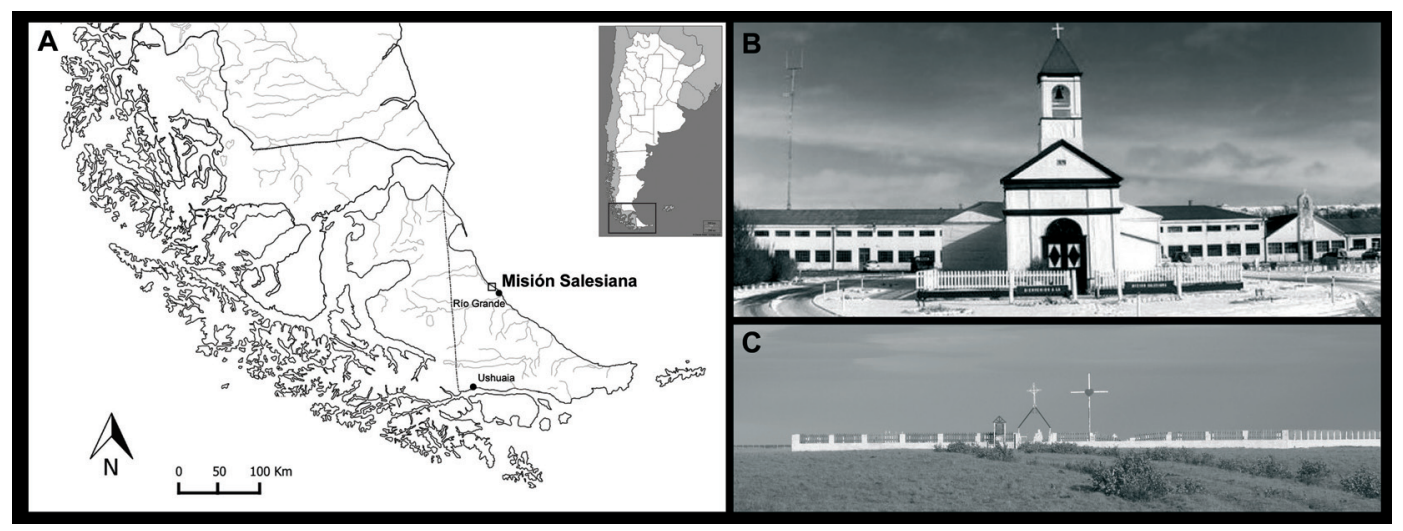

Fig. 1. Misión Salesiana "Nuestra Señora de la Candelaria". a) Mapa de TdF con la localización de la Misión; b) Foto de la Misión; c) Foto del cementerio de la Misión. 
el metro de profundidad y con heterogeneidad en cuanto a las orientaciones (NO-SE, SE-NO, NE-SO y SO-NE). La posición de enterramiento es decúbito supino, con los brazos extendidos o semiflexionados sobre el pecho, en 13 de los individuos; se trata de una posición tradicionalmente ligada al rito cristiano. Los otros tres individuos fueron inhumados en decúbito prono, dos casos y decúbito lateral izquierdo, un sujeto. De los 16 individuos, 14 se encontraban contenidos en cajones de madera, careciendo de ataúd dos de ellos. A su vez, se pudieron recuperar fragmentos textiles, zapatos y/o botones en diez de los sujetos. Los restos óseos objeto de estudio en este trabajo, se encuentran actualmente en el reservorio del Laboratorio de Ecología Evolutiva Humana (LEEH) en la ciudad de Quequén-Necochea. Es importante señalar que los procedimientos desarrollados con los restos humanos están de acuerdo con leyes locales y recomendaciones éticas internacionales. A pesar de ser una muestra reducida, tiene la particularidad de estar acotada temporal y espacialmente, además de contar con información procedente de fuentes históricas, situación poco frecuente en esta región. Se ha de señalar que, a diferencia de la MSLC, los cementerios de las otras dos misiones de la región (Dawson y Ushuaia) hasta el momento no han sido analizados de manera sistemática desde el ámbito de la bioarqueología y la historia (Casali, 2011; García Laborde, 2017). Esta serie de características diferenciales, aportan una mayor relevancia a los análisis que se realizan sobre estos sujetos.

La muestra está conformada por 334 vértebras, 87 cervicales (C), 170 dorsales (D) y 77 lumbares (L), pertenecientes a individuos de ambos sexos (Tabla 1). Seis sujetos son femeninos $(37,5 \%)$ y los 10 restantes, masculinos $(62,5 \%)$.

TABLA 1. Estructura sexo-etaria, porcentaje de completitud y estado de preservación de los 16 individuos estudiados

\begin{tabular}{cccccc}
\hline Individuo & Sexo & $\begin{array}{c}\text { Edad } \\
\text { (años) }\end{array}$ & Completitud (\%) & Preservación & VA $(\mathrm{C}, \mathrm{D}, \mathrm{L})$ \\
\hline C 15-16 & F & $45-60$ & $50-75$ & buena & $23(6,12,5)$ \\
D 15-16 & F & $35-49$ & $75-100$ & mala & $17(2,10,5)$ \\
E 12-13 & M & $35-45$ & $75-100$ & muy buena & $24(7,12,5)$ \\
E 15-16 (3) & M & $35-45$ & $75-100$ & muy buena & $23(7,11,5)^{*}$ \\
E 15-16 (2bis) & M & $30-40$ & $75-100$ & buena & $20(3,12,5)$ \\
E-D 10 & M & $25-45$ & $75-100$ & buena & $24(7,12,5)$ \\
D-C 9-10 & M & $25-40$ & $75-100$ & buena & $24(7,12,5)$ \\
C 15 & M & $25-39$ & $50-75$ & buena & $14(6,6,2)$ \\
C 13 & F & $25-35$ & $50-75$ & buena & $13(0,7,5) * *$ \\
E 10-11 (1) & M & $25-30$ & $75-100$ & muy buena & $24(7,12,5)$ \\
C 7-8 & M & $24-26$ & $75-100$ & muy buena & $24(7,12,5)$ \\
D 16 (bis) & F & $21-45$ & $75-100$ & muy buena & $24(7,12,5)$ \\
C 11 & M & $20-30$ & $75-100$ & muy buena & $17(0,12,5)$ \\
C 14 (2) & F & $19-20$ & $75-100$ & buena & $24(7,12,5)$ \\
E 10-11 (2) & F & $18-25$ & $75-100$ & buena & $24(7,12,5)$ \\
D 14 & M & $18-20$ & $50-75$ & buena & $24(7,12,5)$ \\
\hline
\end{tabular}

VA:vértebras analizadas teniendo en cuenta C, D y L; * no presenta D12, hay continuidad anatómica entre D11 y L1; ** lumbarización craneal:vértebra que presenta arco característico de dorsal inferior (D11, D12), pero que no tiene carillas costales, estando presente la decimosegunda costilla en ambos hemitórax y presentando continuidad anatómica entre D12 y L1. 
La completitud ósea es del 75-100\%, excepto en cuatro casos (C13, C15, C15-16 y D 14). El estado de preservación muestra mayor heterogeneidad, categorizándose los sujetos en bueno y muy bueno, excepto D15-16, que presenta una mala preservación (Tabla 1).

La metodología empleada para la determinación del sexo fue la propuesta por Buikstra y Ubelaker (1994), en la cual se analizan las diferencias morfológicas en una serie de estructuras del cráneo y el coxal. En lo concerniente a la determinación de la edad, se aplicaron los métodos de Todd (1921a, 1921b) y SucheyBrooks (Brooks y Suchey, 1990) para el análisis de la sínfisis púbica, la fusión epifisaria (Buikstra y Ubelaker, 1994) y la metamorfosis del extremo esternal de la cuarta costilla (Bass, 1995; Isçan, Loth y Wright, 1984). El porcentaje de completitud se estimó considerando todos los elementos presentes del individuo en relación con el total de huesos que componen un esqueleto humano adulto. El resultado posteriormente se diferenció en cuatro rangos: $0-25 \% ; 25-50 \% ; 50-75 \%$ y $75-100 \%$ (Buikstra y Ubelaker, 1994). La preservación se analizó a nivel macroestructural, siguiendo los criterios propuestos por González (2007) y por Bello y Andrews (2006), cuantificándose de acuerdo con las siguientes categorías: 1) excelente: su aspecto externo y condición estructural no sufren alteración alguna; 2) muy buena: la macroestructura se encuentra bien conservada, mostrando alguna pérdida de tejido óseo que no modifica sustancialmente su estructura; 3) buena: la superficie externa y/o la integridad del hueso está afectada, implicando la pérdida y/o fragmentación ósea, pero su morfología original puede distinguirse; 4) mala: el grado de fragmentación y pérdida ósea ha alterado significativamente la macroestructura del hueso, perdiendo su integridad (García Laborde, Guichón y González, 2015).

La base metodológica empleada para el estudio del esqueleto axial es el análisis propuesto por Campo (2003, 2015). Este procedimiento analiza las vértebras teniendo en cuenta diversos factores: completitud, caracteres métricos y no métricos, patologías y alteraciones entésicas. Este trabajo se centra en la completitud y en ciertos signos patológicos, tales como nódulos de Schmörl, osteofitos en el cuerpo vertebral, labiación y eburnación en las carillas interarticulares del arco vertebral, así como lesiones en carillas costales, articulación atlantodontoidea y apófisis unciformes.

El estado de preservación del esqueleto axial se determina a través de dos variables: 1) estado de preservación de la columna cuantitativo (EPCN) y 2) estado de preservación de la columna cualitativo total (EPCL); ambas basadas en el grado de completitud de la muestra. El EPCN se calcula teniendo en cuenta el número de vértebras presente en cada sujeto, independientemente del grado de alteración tafonómica, según la fórmula:

$$
\mathrm{EPCN}=\frac{\mathrm{n}^{\mathrm{o}} \text { vértebras presentes }}{\mathrm{n}^{\mathrm{o}} \text { total de vértebras }(24) \times 100}
$$

Mientras que para el cálculo del EPCL total, se emplea la fórmula:

$$
\mathrm{EPCL}=\frac{\sum \text { EPCL parcial }}{\text { valor máximo teórico (7) }}
$$

El EPCL parcial resulta de analizar la completitud de las diferentes estructuras de cada vértebra (cuerpo vertebral y carillas interapofisarias de cada arco vertebral); el valor máximo teórico para el EPCL, es decir un cuerpo completo y los dos arcos con ambas superficies articulares, es de 7 ( 3 cuerpo +2 arco izquierdo +2 arco derecho). Para realizar los cálculos hay que tener en cuenta que el número total de vértebras es 24, excepto para aquellos casos que presenten alteraciones en el número de elementos (Campo 2003, 2015).

En lo que respecta a las patologías que afectan al cuerpo vertebral: a) nódulos de Schmörl, se registra su presencia en cada uno de los platillos, el superior (S) y el inferior (In), de manera independiente. Los nódulos se categorizan en dos grados teniendo en cuenta la expresión de la lesión: 1) moderada; 2) marca$\mathrm{da}$, cuando penetra en el tejido intraesponjoso o presenta una profundidad considerable. La superación del borde marginal, en aquellos casos en que se aprecie, se indica en las observaciones; b) osteofitos en el cuerpo vertebral, se analiza cada platillo de manera independiente, subdividiendo estos en izquierda (I) y derecha (D), usando como eje un hipotético plano 
sagital. Las lesiones se agrupan en 3 grados: 1) anillo elevado con mayor pronunciamiento del borde; 2) espículas curvadas y/o grandes viseras; 3) anquilosis o fusión; c) artrosis atlantodontoidea, se indica su presencia o ausencia en las vértebras afectadas, atlas y axis; d) uncoartrosis, cuando la lesión se aprecia, se indica. Teniendo en cuenta ambos platillos y lados, esta patología se registra en el platillo In del axis, C3, C4, C5, C6, C7 y el platillo S de D1; e) artrosis en las carillas costales, se registra la presencia o ausencia de lesión bien la carilla I o en la D. La artrosis costal se produce en la articulación vertebrocostal, por tanto, en las 12 vértebras dorsales. En estos últimos tres casos, las lesiones pueden presentar labiación o eburnación. Sin embargo, solo se detalla la presencia o ausencia de lesiones.

También se registra la artrosis posterior, es decir, aquella que afecta a las diferentes estructuras presentes en el arco vertebral. Se analiza la artrosis en las cuatro carillas articulares existentes por vértebra: superior izquierda (SI), superior derecha (SD), inferior izquierda (InI), inferior derecha (InD); cada una de ellas se estudia independientemente teniendo en cuenta: a) labiación, puede expresarse de tres maneras: 1) relieve afilado, a veces rizado con espículas; 2) formación extensa de espículas; 3) anquilosis; b) eburnación, se aprecian dos estados: 1- sólo pulido; 2- pulido con macroporosidad, típica superficie pulida de aspecto nacarado. Se ha de puntualizar, que tanto en las lesiones del cuerpo como de las carillas interapofisarias se tuvo en cuenta la expresión máxima observada.

En cada uno de los análisis, las frecuencias se obtuvieron teniendo en cuenta los casos que presentaban lesiones con respecto al número de vértebras observables en cada una de las categorizaciones realizadas. Con el fin de analizar la existencia de diferencias significativas por motivos de sexo, se realizaron test estadísticos teniendo en cuenta regiones $(\mathrm{C}, \mathrm{D}, \mathrm{L}) \mathrm{y}$ vértebras: $\chi^{2}$ de Pearson en las carillas interapofisarias (labiación y eburnación) y $\mathrm{F}$ exacta de Fisher en nódulos de Schmörl y osteofitos del cuerpo. Para el tratamiento y manejo de los datos, así como para los análisis estadísticos se han utilizado los programas SPSS Statistics v. 22.0 y Past 3.16 .

\section{RESULTADOS}

La muestra analizada presenta un estado de preservación que podría considerarse muy bueno (Tabla 2); las variables EPCN (análisis cuantitativo) y EPCL (análisis cualitativo) reflejan valores superiores al $80 \%$ en 12 de los 16 individuos. En lo que respecta al EPCN, cabe destacar que nueve casos muestran una preservación del 100\% y que sólo dos se sitúan en valores inferiores al 70\%. En cuanto al EPCL, 11 individuos se encuentran por encima del $85 \%$, y los cinco restantes entre el $45 \%$ y el $75 \%$.

En lo concerniente a las patologías observadas en los cuerpos vertebrales, los nódulos de Schmörl se encuentran en un $75 \%$ de los individuos (12 de los 16). Principalmente, aparecen en las regiones dorsal y lumbar, distribuidos mayoritariamente entre D6 y L5, con un valor máximo en D11; fuera de este rango se observa un único caso, situado en C5 (Fig. 2). En cuanto al grado de las lesiones, predominan

TABLA 2. Porcentajes de EPCN y EPCL de cada individuo

\begin{tabular}{ccc}
\hline Individuo & EPCN (\%) & EPCL (\%) \\
\hline C 15-16 & 95,8 & 89,3 \\
D 15-16 & 70,8 & 46,4 \\
E 12-13 & 100 & 97,0 \\
E 15-16 (3) & 95,8 & 95,8 \\
E 15-16 (2bis) & 83,3 & 62,5 \\
E-D 10 & 100 & 100 \\
D-C 9-10 & 100 & 97,0 \\
C 15 & 58,3 & 58,3 \\
C 13 & 54,2 & 47,0 \\
E 10-11 (1) & 100 & 92,3 \\
C 7-8 & 100 & 100 \\
D 16 (bis) & 100 & 100 \\
C 11 & 70,8 & 70,8 \\
C 14 (2) & 100 & 100 \\
E 10-11 (2) & 100 & 100 \\
D 14 & 100 & 86,3 \\
\hline Media & 89,32 & 83,93 \\
\hline
\end{tabular}

EPCN:estado de preservación de la columna cuantitativo; EPCL:estado de preservación de la columna cualitativo total. 


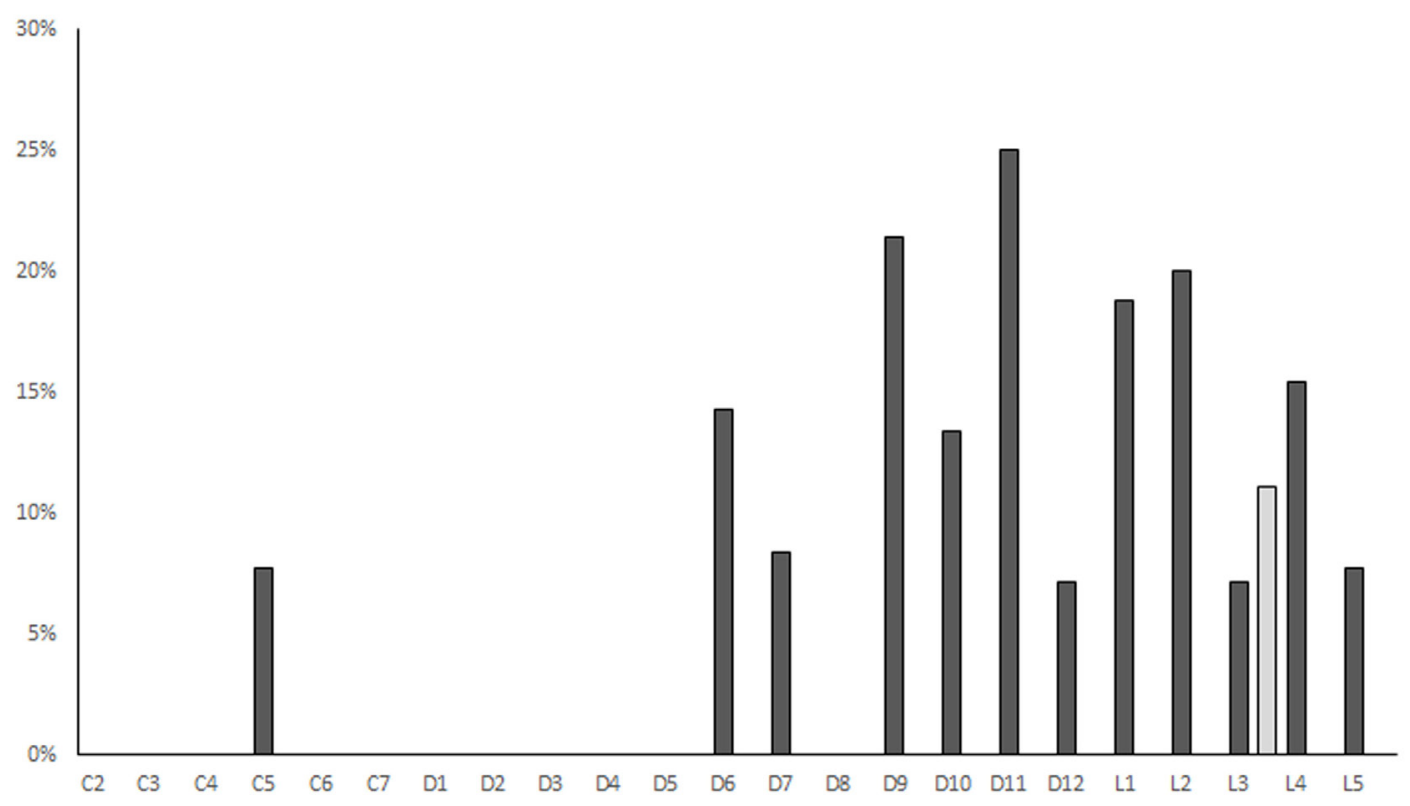

Fig. 2. Frecuencias de casos de nódulos de Schmörl según las vértebras afectadas en la MSLC (negro) respecto a los resultados del norte de Tierra del Fuego (gris) presentados por Suby (2014).

los casos moderados (grado 1) frente a los marcados (grado 2) (Fig. 3D), ambos distribuidos de manera homogénea. Los nódulos son más frecuentes en los platillos inferiores que en los superiores. No hay diferencias significativas en la prevalencia de la lesión por sexo $\left(\mathrm{Fp}_{\text {vér- }}\right.$ tebra: $\left.: 0,49 ; \mathrm{Fp}_{\text {región }}: 0,31\right)$ (Tabla 3), si bien afecta más a los individuos de sexo masculino (Tabla 4).

Los osteofitos en los márgenes de los cuerpos vertebrales muestran un aumento de los signos cráneo-caudalmente, siendo la región más afectada la lumbar (Tabla 4). Si se atiende a las frecuencias, puede apreciarse un mínimo a nivel de $\mathrm{C} 2$ seguido por un aumento progresivo hasta la vértebra $\mathrm{C} 4$. Entre C4 y D2 se observan valores intermedios, mientras que entre D3 y L5 se encuentran los valores máximos, siendo estos D4, D10, L1 y L2 (Fig. 4). Se observan osteofitos en $75 \%$ de los individuos estudiados (12 de 16). Existen diferencias con respecto al sexo, presentando los individuos masculinos una mayor prevalencia de la patología en todos los segmentos, si bien esta

TABLA 3. Diferencias por sexo en la prevalencia de diferentes lesiones. Test de Chi cuadrado y exacto de Fisher

\begin{tabular}{ccccc}
\hline & \multicolumn{2}{c}{ Por vértebra } & \multicolumn{2}{c}{ Por región } \\
\cline { 2 - 5 } & $\begin{array}{c}\text { Chi cuadrado }(\chi 2) \\
\text { Significación }\end{array}$ & $\begin{array}{c}\text { Test exacto de Fisher } \\
\text { Significación }\end{array}$ & $\begin{array}{c}\text { Chi cuadrado }(\chi 2) \\
\text { Significación }\end{array}$ & $\begin{array}{c}\text { Test exacto de Fisher } \\
\text { Significación }\end{array}$ \\
\cline { 2 - 5 } Nódulos de Schmörl & 0,33193 & 0,49484 & 0,23561 & 0,30998 \\
Osteofitos & 0,99878 & 0,99975 & 0,11028 & 0,12695 \\
Labiación & 0,99614 & no disponible & 0,19896 & no disponible \\
Eburnación & 0,99938 & no disponible & 0,58364 & no disponible \\
\hline
\end{tabular}

Valor de significación para prevalencia de nódulos de Schmörl, osteofitos en el cuerpo vertebral, labiación y eburnación de las carillas interapofisarias. 


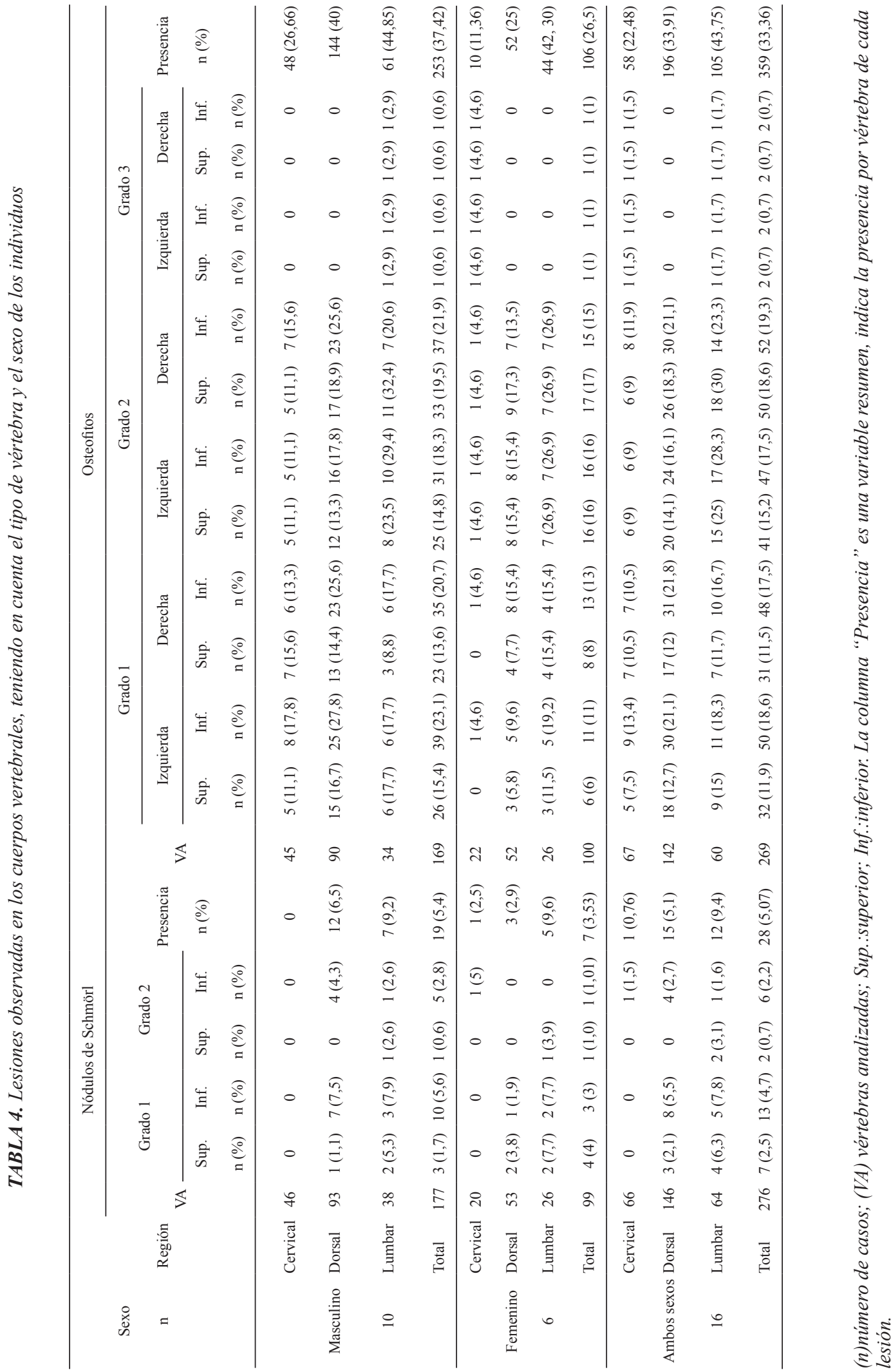




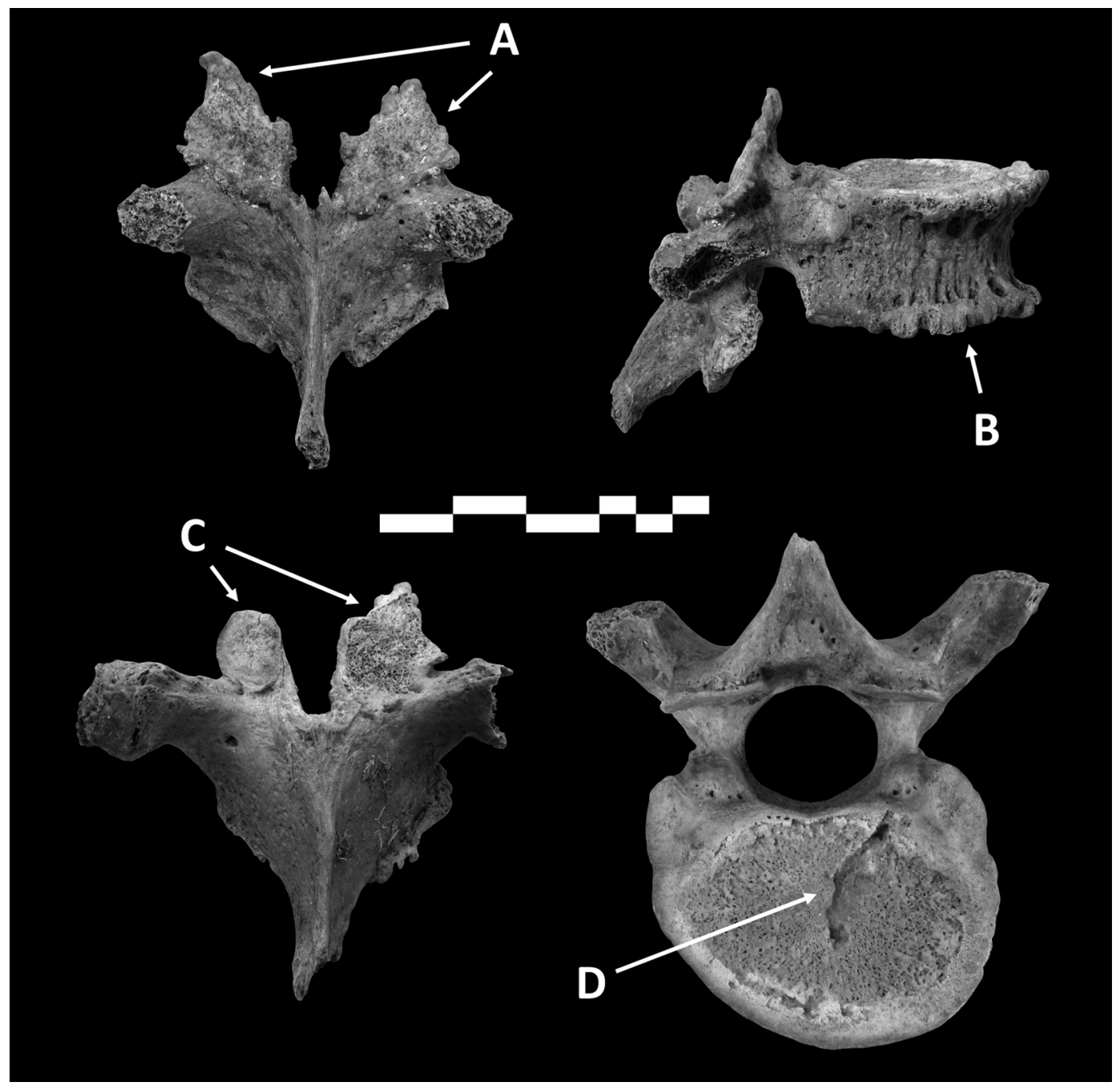

Fig. 3. Lesiones observadas en la MSLC. A) carillas articulares con presencia de eburnación (grado 2) y labiación (grado 3); B) osteofitos en cuerpo vertebral en forma de grandes viseras; C) carillas articular izquierda y carilla derecha con eburnación (grado 2) y labiación (grado 3); D) nódulo de Schmörl (grado 2).

diferencia se hace más notable en las regiones cervical y dorsal (Tabla 4). Sin embargo, tales diferencias no son significativas $\left(\mathrm{Fp}_{\text {vértebra }}: 0,99\right.$; $\mathrm{Fp}_{\text {región }}: 0,12$ ) (Tabla 3).

La artrosis atlantodontoidea se observa en cerca de un tercio de los individuos (4 de 13) que presentaban estas vértebras. En todos aquellos casos en los que se han apreciado signos artrósicos en el atlas, se han observado también en el axis. Únicamente en un caso, se apreciaron lesiones en la apófisis odontoidea y no así en el atlas (Tabla 5).

La uncoartrosis muestra un patrón claro, con valores mínimos en los extremos y máxi- mos en la región intermedia. Presenta un mínimo relativo en $\mathrm{C} 2$, aumenta hasta $\mathrm{C} 4$, vértebra en la que se alcanza el valor máximo; para a continuación, descender hasta el mínimo absoluto que se aprecia en D1. Esta lesión muestra una prevalencia del 61,5\% (8 de 13 individuos, 3 sujetos no presentan condiciones de análisis).

Se registra artrosis de las carillas costales de los cuerpos vertebrales en todas las vértebras de la región dorsal, a excepción de D4. Las lesiones se localizan principalmente en zonas transicionales, D1 y D12, donde se pueden observar sus frecuencias más altas. En las vértebras D5-D6 existe un máximo relativo, 


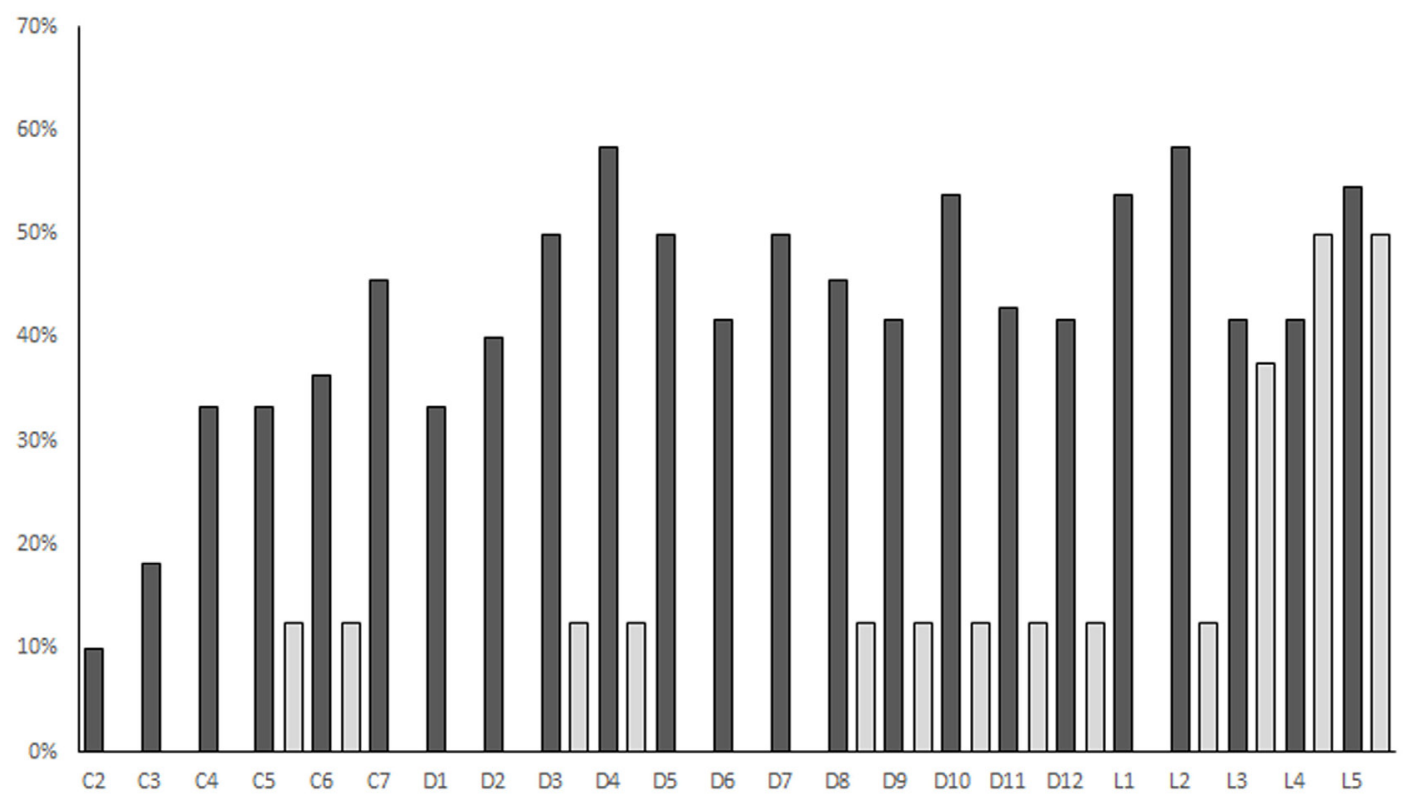

Fig. 4. Osteofitos en los márgenes de los cuerpos vertebrales en la MSLC (negro) comparados con los resultados del norte de Tierra del Fuego (gris) presentados por Suby (2014).

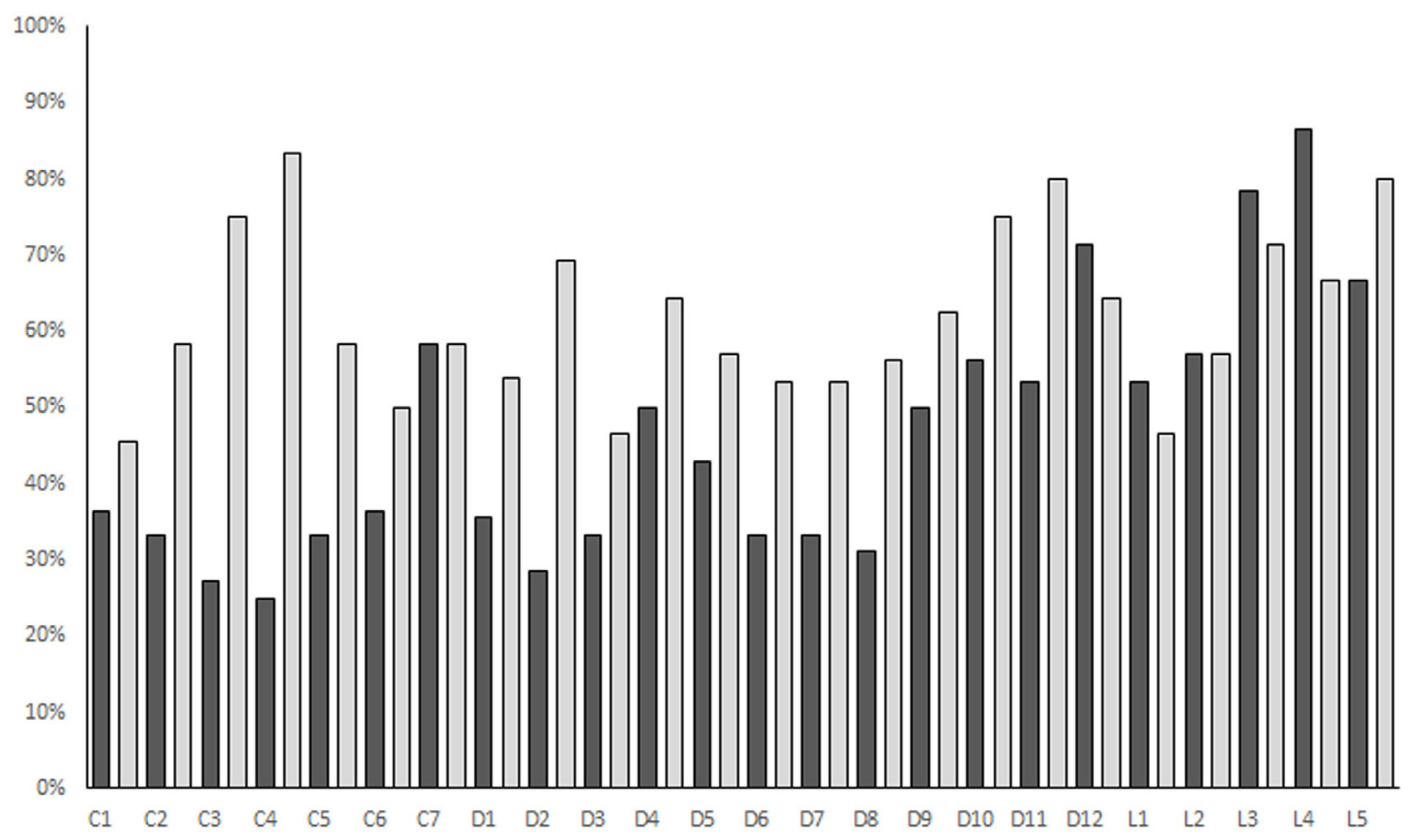

Fig 5. Frecuencias de labiación (gris oscuro) y eburnación (gris claro) en las carillas articulares interapofisarias según las vértebras afectadas. 
TABLA 5. Frecuencia de individuos con artrosis atlantodontoidea

\begin{tabular}{rcc}
\hline & $\begin{array}{c}\text { Ausencia } \\
\mathrm{n}(\%)\end{array}$ & $\begin{array}{c}\text { Presencia } \\
\mathrm{n}(\%)\end{array}$ \\
\hline $\mathrm{C} 1$ & $8(66,7)$ & $4(33,3)$ \\
$\mathrm{C} 2$ & $9(75,0)$ & $3(25,0)$ \\
Ind. & $9(69,2)$ & $4(30,8)$ \\
\hline
\end{tabular}

Ind.: Indeterminada; n: número de casos.

pero de una magnitud menor. Esta afección se aprecia en el $81,2 \%$ de los sujetos estudiados (13 de 16).

Entre las lesiones de carácter artrósico que afectan a los arcos vertebrales, se observa una progresión ascendente de las frecuencias cráneo-caudalmente; tanto en el caso de la labiación, como en el de la eburnación de las carillas interapofisarias (Fig. 5). Sin embargo, cada uno de los signos ofrece una distribución diferente de máximos y mínimos relativos. Para la labiación se encuentran mínimos en $\mathrm{C} 3-\mathrm{C} 4$, D2, D6-D8, D11, L1-L2 y L5; y máximos en C1-C2, C7, C4, D10, D12 y L4. Mientras que los mínimos para la eburnación se localizan en C1, C6, D3, D5-D7 y L1, y los máximos se sitúan en C4, D2, D4, D10-D11 y L5. Todos los individuos presentan eburnación y labiación. Con respecto a la prevalencia de los signos patológicos en relación con el sexo, la labiación tiene una mayor prevalencia en los individuos masculinos, excepto en la región dorsal, aunque estas diferencias no son significativas $\left(\chi^{2} \mathrm{p}_{\text {vértebra }}: 0,99 ; \chi^{2} \mathrm{p}_{\text {región }}: 0,19\right)$ (Tabla 3$)$. Sin embargo, la eburnación es más frecuente en los sujetos femeninos, fundamentalmente en la región torácica, si bien estas diferencias tampoco son significativas $\left(\chi^{2} \mathrm{p}_{\text {vértebra }}: 0,99 ; \chi^{2} \mathrm{p}_{\text {región }}: 0,58\right)$ (Tablas 3 y 6).

\section{DISCUSIÓN}

El buen estado de preservación que reflejan los valores de EPCN y EPCL, facilita la caracterización y análisis en detalle del aspecto macroscópico de los elementos óseos. La escasa alteración tafonómica de los restos óseos estudiados podría estar relacionada con la acción combinada de diferentes factores. En primer lugar, los valores de $\mathrm{pH}$ que presentan los sedimentos se encuentran entre 7,35 y 5,85 (García Laborde et al., 2015), siendo el valor promedio de todas las mediciones realizadas próximo a la neutralidad ( $\mathrm{pH}: 6,94)$. Valores extremos del $\mathrm{pH}$, producen pérdida por hidrólisis de la porción proteica del hueso, debido a que los iones de hidrogeno pueden reemplazar el calcio contenido en la bioapatita (Gutiérrez, 2004). De la misma manera, Gordon y Buikstra (1981) señalan que existe una fuerte correlación inversa entre el $\mathrm{pH}$ y el estado de preservación de los huesos. En segundo lugar, las bajas temperaturas ambientales y edáficas tienden a inhibir y retardar la acción de los microorganismos (Tibbet y Carter, 2009). En tercer lugar, las texturas gruesas del suelo características del cementerio de la MSLC retienen menos humedad que las finas (García Laborde et al., 2015). Por último, cabe contemplar la incidencia de los factores culturales: a) la inhumación de los individuos a una profundidad aproximada de un metro influye en la velocidad de descomposición (Rodríguez y Bass, 1985), con lo que no sólo se evita el impacto de la meteorización, principalmente la acción erosiva del viento (Santiago et al., 2011; Suby et al., 2008), sino también desciende considerablemente la tasa de descomposición; b) la existencia de ataúdes de madera en los cuales fueron inhumados los sujetos, a excepción de E10-11 (2) y D16 (bis); c) la presencia de vestimentas en 10 de los individuos analizados y d) las diferentes posiciones de enterramiento encontradas, decúbito prono, supino y lateral izquierdo. No se observan diferencias en cuanto a la preservación debido a la influencia cultural. En suma, las condiciones de $\mathrm{pH}$, ambientales, edáficas, así como culturales específicas del cementerio de la MSLC dan como resultado un buen estado de preservación que facilita el relevamiento paleopatológico macroscópico.

En lo que respecta a las lesiones presentes en el cuerpo vertebral, la distribución de los nódulos de Schmörl presenta una mayor prevalencia en la región D6-L5, con un máximo en D11. Estos resultados coinciden con la muestra estudiada por Suby (2014), procedente de la región continental de Santa Cruz/Magallanes, si bien en este caso los valores máximos se encuentran entre L2 y L4. Ambos casos se encuadran 


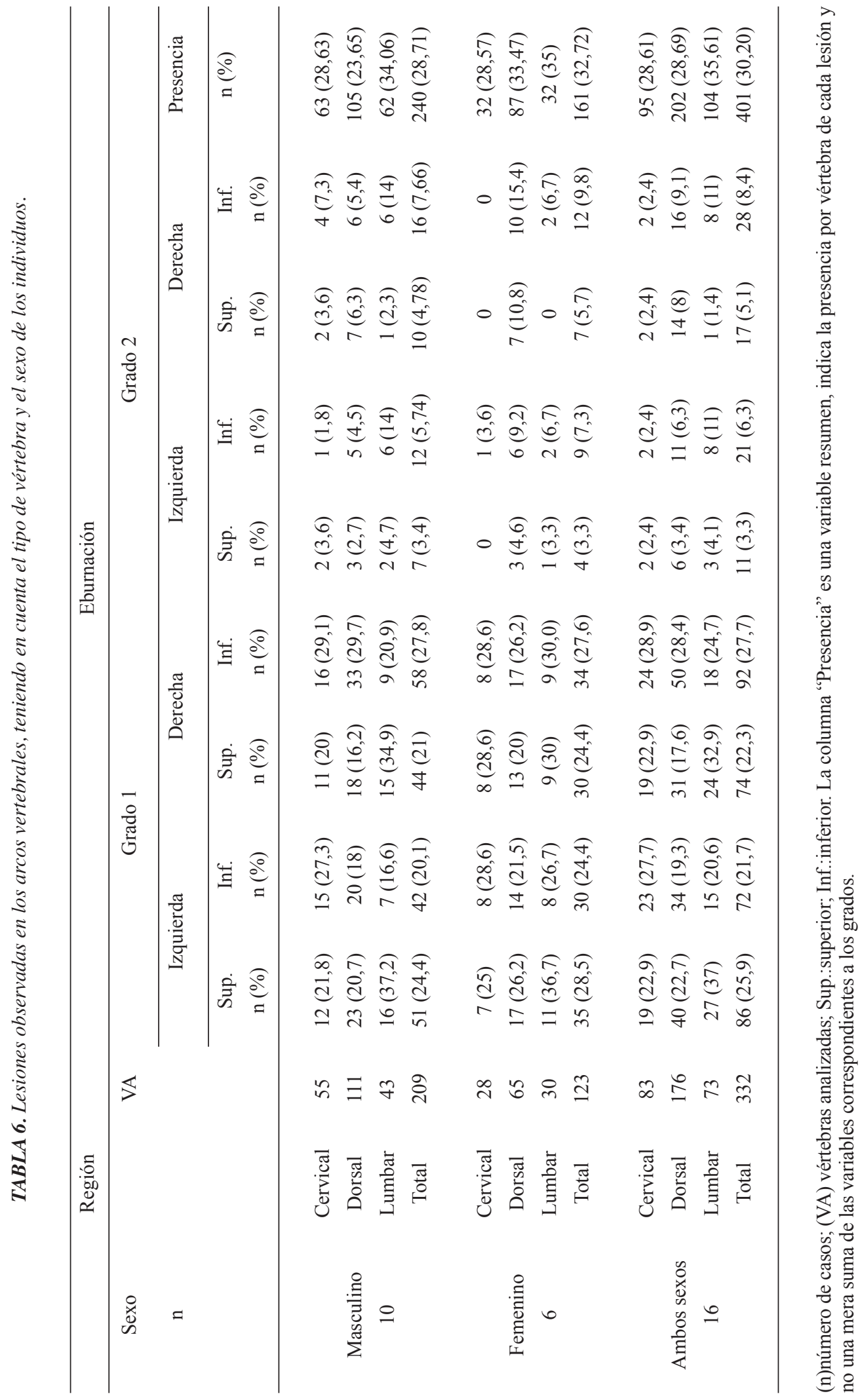




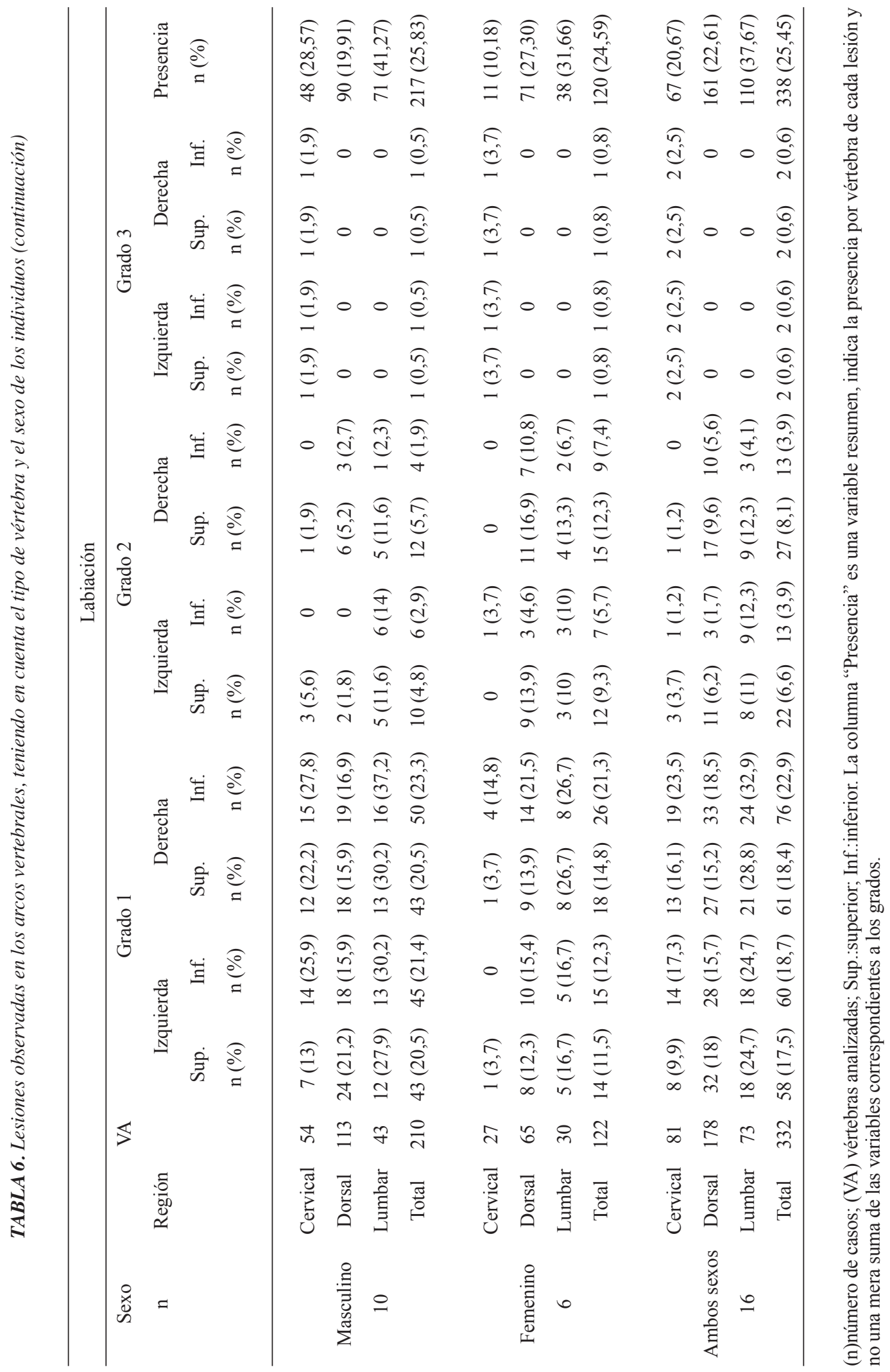


dentro de lo que señala la literatura acerca de esta patología, indicando que, aun cuando las lesiones pueden aparecer en cualquier vértebra, son más frecuentes en la región dorso-lumbar (Dar et al., 2010), encontrando un máximo en la zona transicional que ocupan D11 (Dar et al., 2010) y D12 (Üstündağ, 2009; Burke, 2012). Autores como Üstündağ (2009), interpretan que la escasa aparición de este tipo de lesiones en las vértebras cervicales podría deberse a que los discos intervertebrales de esta región son relativamente gruesos y la carga a la que está sometida es mucho menor que en el resto de la columna. Respecto al grado y la presencia de las lesiones, a pesar de existir un predominio de los casos moderados frente a los marcados, la prevalencia de los nódulos de Schmörl en la MSLC es del 75\% (12/16 individuos). Este valor de la prevalencia en la MSLC, prácticamente triplica el $27,3 \%$ (6/22 sujetos) observado en muestras no evangelizadas pre y post contacto de la región, siendo seis veces superior al 12,5\% (1/8 individuos) al que presentan los individuos del norte de la Isla Grande de TdF (Suby, 2014), lugar en el que se encuentra la misión. El 75\% de prevalencia observado en los individuos de la MSLC puede considerarse un valor alto para un contexto arqueológico (Suby, 2014; Üstündağ, 2009), no así en el ámbito clínico, donde se observan resultados equivalentes (Hilton, Ball y Benn, 1976). Se encuentran con mayor frecuencia en los individuos de sexo masculino (8/10 de los sujetos, el $80 \%$ ) que en los femeninos (4/6 de los individuos, el 66\%). Este mismo patrón, de mayor prevalencia en el sexo masculino es también apreciado por Jiménez-Brobeil, RocaRodríguez, Al Oumaoui y du Souich (2012) y Schmörl y Junghanns (1959). La presencia de nódulos de Schmörl se asocia a factores tales como la actividad física y el estrés mecánico (Jiménez-Brobeil, Al Oumaoui y du Souich, 2010). Sin embargo, estudios recientes sostienen que estas lesiones no son un buen indicador de actividad, al encontrarse fuertemente ligadas a factores genéticos (Dar et al., 2010 y Williams et al., 2007). Se han de indicar dos factores que caracterizan a los individuos que habitaron PA: por un lado, una cierta homogeneidad genética, como indican los análisis de ADN mitocondrial (de la Fuente et al., 2015; Lalueza, 1995); por otro, el drástico cambio en el estilo de vida que supuso la llegada de los europeos, pasando de un estilo nómada a otro sedentario misional (Casali, 2011). Si tenemos en cuenta que los individuos analizados por Suby (2014) y los estudiados en este trabajo se encuentran próximos genéticamente, podría señalarse el estilo de vida como un factor diferencial influyente. Sin embargo, el debate acerca de la etiología de estas lesiones, así como su posible origen multifactorial, nos lleva a no asumir el cambio en el estilo de vida y las consecuentes variaciones en la actividad física como única causa posible de esa diferencia. En relación con la distribución de las lesiones, nuestros resultados señalan una mayor frecuencia de los nódulos en los platillos inferiores $(67,9 \%)$, frente a los superiores $(32,1 \%)$. Así lo han observado autores como Dar et al. (2010): $62,3 \%$ inferiores, frente a $37,7 \%$ superiores; o Faccia y Williams (2008): 53,3\% inferiores y 45,7\% superiores; o Campo (2015). Del mismo modo en PA, Suby (2014) observa una mayor prevalencia de nódulos de Schmörl en la superficie inferior $(60,7 \%)$ respecto de la superficie superior $(39,2 \%)$.

Otra de las patologías que presenta el cuerpo son los osteofitos, cuya tendencia es de un ligero aumento de las lesiones desde la región cervical hasta la lumbar. Patrón similar al presentado en otras muestras (Campo, 2015; Novak y Slaus, 2011; Rojas-Sepúlveda, Ardagna y Dutour, 2008; Üstündağ, 2009; Van der Merwe; Işcan y L'Abbè, 2006; Waldron, 1991) y en las regiones norte y sur de TdF (Suby, 2014). En lo que concierne a las muestras de la región del norte de $\mathrm{TdF}$, existe una diferencia apreciable entre la prevalencia de las muestras pre y postcontacto y las de la MSLC, siendo las diferencias: 1) región cervical, 3,5\% pre y post, frente al $29,8 \%$ de la MSLC; 2) región dorsal, 7,3\% frente al 45,8\%, y; 3) región lumbar, $30 \%$ frente a $50 \%$. Por lo tanto, igual que sucedía en el caso de los nódulos de Schmörl, se observa un aumento de lesiones respecto a los sujetos pre y postcontacto de la región norte de TdF estudiados por Suby (2014), confirmándose de esta manera los resultados obtenidos en trabajos anteriores (D'Angelo del Campo et al., 2017; García Laborde 2017; García Laborde et al., 2010, 2014). Sin embargo, existen otros patrones tanto en PA (muestra de Santa Cruz/Magallanes: Suby, 2014), como de poblaciones de otras regiones del mundo (Jur- 
main y Kilgore, 1995). Autores como Üstündağ (2009) o Jurmain y Kilgore (1995) relacionan la osteofitosis vertebral con la curvatura de la columna vertebral. En el mismo sentido, Van der Merwe et al. (2006) sostienen que el desarrollo osteofítico diferencial a lo largo de la columna, puede deberse a factores como la posición de la vértebra dentro de la línea de gravedad, la movilidad de la articulación y el peso soportado. Si se atiende a las diferencias por sexos, se aprecia que los sujetos masculinos presentan una mayor prevalencia en todas las regiones, si bien esta diferencia se hace más notable en las zonas cervical y dorsal. La presencia de uncoartrosis es mínima en las dos zonas de transición, C2 y C7-D1. Esta distribución diferencial podría estar relacionada con las curvaturas del esqueleto axial y sus compromisos biomecánicos, dado que se ajustan al patrón observado por Üstündağ (2009) o Jurmain y Kilgore (1995) para la artrosis anterior. A pesar de tratarse de una variable poco habitual, existen estudios que recogen la presencia de uncoartrosis; es el caso del trabajo de Campo (2015) donde observa un patrón decreciente craneocaudal de las frecuencias, desde el axis hasta C6, en una población medieval de la península ibérica.

En cuanto a la artrosis atlantodontoidea, está presente en aproximadamente el 30\% de los individuos, valor ligeramente inferior al $42-49 \%$ observado por otros autores (Campo, 2015; Pálfi Dutour, Berato y Marcsik, 1994). Mientras que Campo (2015) encuentra una correspondencia entre ambas vértebras en 22 de 24 casos (92\%), en la MSLC sucede en 3 de 4 casos (75\%); las diferencias pueden ser atribuibles al reducido tamaño muestral manejado en este trabajo.

Igual que la artrosis anterior manifestaba cierto paralelismo, cuando se representa gráficamente, con las curvaturas de la columna, la artrosis de las carillas costales podría estar relacionada con la estructura biomecánica del esqueleto axial. Resulta llamativo que sean las zonas de transición, representadas por D1 y D12, las que muestran las frecuencias más altas de artrosis y que, por el contrario, la zona de dorsales intermedias sea la que presenta unos valores más bajos, coincidiendo con la máxima cifosis fisiológica. No se han realizado análisis sistemáticos de este signo sobre muestras de individuos en las proximidades de TdF, aunque en la literatura sí se menciona la presencia de artrosis en las carillas costales en el estudio de casos aislados (Alfonso-Durruty et al., 2011).

En lo concerniente a las carillas articulares interapofisarias, se observa que, en el caso de la labiación, el escaso número de evidencias dificulta el estudio de posibles pautas de distribución; no así la información concerniente a la eburnación. Las máximas frecuencias de eburnación $(\mathrm{C} 4, \mathrm{D} 2$, D4, D10-D11 y L5) ofrecen una distribución muy similar a la expuesta por autores como Knüsel, Göggel, y Lucy (1997), máximos en C3-C4, C7D1, D4-D5, D10-D11 y L4-L5 ó Jurmain y Kilgore (1995), máximos en C4-C5, C7-D1, D2-D3, D5-D6, D11-D12, L3-L4. Este resultado respalda los criterios metodológicos empleados y señala a la eburnación, signo patognomónico de la artrosis (Rogers y Waldron, 1995), como un indicador de artrosis vertebral posterior mucho más preciso que la labiación.

Por último, es importante señalar que, aunque se escapa de los objetivos de este trabajo, en términos generales se observa una mayor presencia de lesiones en individuos de mayor edad. Sin embargo, teniendo en cuenta la limitación de las metodologías para la determinación de la edad, que nos ha llevado a considerar a los individuos simplemente como adultos, así como lo limitado del tamaño muestral, no nos aventuramos a señalar nada en este aspecto. Trabajos futuros que incluyan el análisis del esqueleto completo podrán arrojar resultados más concluyentes en cuanto a la relación entre el proceso de envejecimiento y determinadas lesiones óseas.

\section{CONCLUSIONES}

Los individuos inhumados en el cementerio de la MSLC se caracterizan por pertenecer a un contexto espacio-temporal documentado de gran valor histórico, y por su buen estado de preservación. El análisis de la distribución y frecuencia de los signos de espondiloartrosis y nódulos de Schmörl, refleja que no existen diferencias notables respecto a muestras de otras regiones del mundo. Sin embargo, sí se observan diferencias con otras muestras de la región pre y post-contacto, apreciándose un aumento considerable en la prevalencia de nódulos de Schmörl y osteofitos del cuerpo vertebral en los individuos de la MSLC. 
A nivel metodológico, la uncoartrosis se revela como un buen indicador de la artrosis anterior cervical, con un carácter informativo superior al de los osteofitos en el cuerpo vertebral. Del mismo modo, la eburnación resulta ser un indicador más específico de la artrosis posterior que la labiación. La artrosis en las carillas articulares costales, con un marcado patrón de distribución, merecen una mayor atención en futuros estudios.

Este trabajo es una primera aproximación en el análisis detallado de la columna vertebral en PA. En un futuro sería conveniente ampliar los análisis a otros sujetos de la región, con distintas procedencias geográficas y cronológicas, permitiéndonos profundizar los resultados obtenidos $\mathrm{y}$, de paso, ahondar en el conocimiento tanto de la región como del posible efecto que pudo tener el contacto interétnico en las poblaciones originarias.

\section{AGRADECIMIENTOS}

Este trabajo fue parcialmente financiado por el proyecto PICT 0575 (Agencia Nacional de Promoción Científica y Tecnológica, Ministerio de Ciencia, Tecnología e Innovación Productiva, Argentina) y se enmarca en un programa de investigación iniciado en 2006, a través de los proyectos PICT 1530 y PICT 13889. Los autores queremos agradecer a Patricia I. Palacio por su colaboración en la realización de mapas e imágenes presentadas en este artículo.

\section{Nota}

${ }^{1}$ Últimas estribaciones del continente americano y los archipiélagos fueguinos.

\section{LITERATURA CITADA}

Alfonso-Durruty, M. P., Calás, E. y Morello, F. (2011). Análisis Bioantropológico de un enterramiento humano del Holoceno Tardío en Cabo Nose, Tierra del Fuego, Chile. Magallania, 39 (1), 147-162. doi: 10.4067/S071822442011000100009

Aspillaga, E. C., Ocampo, C. y Rivas, P. H. (1999). Restos óseos humanos de contextos arqueológicos del área de isla Navarino: indicadores de estilo de vida en indígena canoeros. Anales del Instituto de la Patagonia, serie Ciencias Humanas, 27, 123-135.

Bass, W. M. (1995). Human Osteology. A laboratory and field manual. Columbia, Estados Unidos: Spetial $\mathrm{Pu}-$ blicacion $\mathrm{N}^{\circ} 2$ of the Missouri Archaeological Society.

Bello, S. M. y Andrews, P. (2006). The intrinsic pattern of preservation of human skeletons and its influence on the interpretation of funerary behaviors. En R. Gowland, y C. Knüsel (Eds.). The Social Archaeology of Funerary Remains (pp. 1-13). Oxford, Inglaterra: Oxbow Books.

Brooks, S. T. y Suchey, J. M. (1990). Skeletal Age Determination Based on the Os Pubis: A Comparison of the Acsádi-Nemeskéri and Suchey-Brooks Methods. $\mathrm{Hu}$ man Evolution, 5, 227-238.

Buikstra, J. E. y Ubelaker, D. H. (1994). Standards for data collection from human skeletal remains. Arkansas, Estados Unidos: Arkansas Archaeological Survey Research Series $\mathrm{N}^{\circ} 44$.

Burke, K. L. (2012). Schmörl's Nodes in an American Military Population: Frequency, Formation, and Etiology. Journal of Forensic Science, 57 (3), 571-577. doi: 10.1111/j.1556-4029.2011.01992.x

Campo, M. (2003). Paleopatología de la columna vertebral. En A. Malgosa, A. Isidro (Eds.). Paleopatología la enfermedad no escrita. (pp. 403-415). Barcelona, España: Masson.

Campo, M. (2015). Paleopatología de la columna vertebral en la población hispanomusulmana de San Nicolás (Murcia, S. XI-XIII) (Tesis doctoral). Facultad de Medicina, Universidad Complutense de Madrid, Madrid.

Casali, R., Fugassa, M. H. y Guichón, R. A. (2009). Nuevos datos sobre la Misión Salesiana La Candelaria, Rio Grande, Tierra del Fuego. En F. Santiago, M. Salemme, M. Alvarez, E. Piana, M. Vazquez, M. E. Mansur (Eds.). Arqueología de la Patagonia - una mirada desde el último confin (pp. 577-612). Ushuaia, Argentina: Utopías.

Casali, R. (2011). Contacto interétnico en el norte de Tierra del Fuego: La Misión Salesiana La Candelaria (Río Grande) y la salud de la población Selk'nam (18951931) (Tesis doctoral). Facultad de Historia, Universidad Nacional de Mar del Plata, Mar del Plata.

Castro, M. y Aspillaga, E. (1991). Fuegian Paleopathology. Antropología Biológica, 1, 1-13.

Chapman, A. (1977). Economía y estructura social de la sociedad Selk'nam (Tierra del Fuego). Journal de la Société des Américanistes, 64 (1), 135-148.

Constantinescu, F. C. (1997). Hombres y mujeres del cerro Los Onas: presentes, ausentes ... los relatos de sus huesos. Anales del Instituto de la Patagonia, serie Ciencias Humanas, 25, 59-74.

Constantinescu, F. C. (1999). Evidencias bioantropológicas para modos de vida cazador recolector terrestre y marítimo en los restos humanos óseos de Tierra del Fuego. Anales del Instituto de la Patagonia, serie Ciencias Humanas, 27, 137-174.

D’Angelo del Campo, M. D., Suby, J. A., García-Laborde, P. y Guichón, R. A. (2017). Spondylolysis in the past: A case study of hunter-gatherers from Southern Patagonia. International Journal of Paleopathology, 19, 1-19. doi: 10.1016/j.ijpp.2017.07.001

Dar, G., Masharawi, Y., Peleg, S., Steinberg, N., May, H. y Medlej, B. (2010). Schmörl's nodes distribution in the human spine and its possible etiology. European Spine Journal, 19, 670-675. doi: 10.1007/s00586-009-1238-8

de la Fuente, C., Galimany, J., Kemp, B. M., Judd, K., Reyes, O. y Moraga, M. (2015). Ancient marine huntergatherers from Patagonia and Tierra del Fuego: diversity and differentiation using uniparentally inherited genetic markers. American Journal of Physical Anthropology, 158 (4), 719-729. doi: 10.1002/ajpa.22815

Faccia, K. J. y Williams, R. C. (2008). Schmorl's nodes: clinical significance and implications for the bioarchaeological record. International Journal of Osteoarchaeology, 18 (1), 28-44. doi: 10.1002/oa.924 
García Laborde, P. (2017). Estado nutricional de la población Selk'nam: aproximación bioarqueológica al impacto generado por la misionalización. Misión Salesiana Nuestra Señora de La Candelaria, Tierra del Fuego (Siglos XIX-XX) (Tesis doctoral). Facultad de Ciencias Sociales, Universidad del Centro de la Provincia de Buenos Aires, Olavarría.

García Laborde, P., Guichón, R. A. y González, N. G. (2015). Una aproximación tafonómica al antiguo cementerio de la Misión Salesiana de Río Grande, Tierra del Fuego. Arqueología, 21 (2), 277-290.

García Laborde, P., Valenzuela, L. O. y Guichón R. A. (2014). Sinergismo entre indicadores de stress metabólico-nutricional y de enfermedades infecciosas en la misión salesiana de Rio Grande, Tierra del Fuego. Actas II Taller Nacional de Bioarqueología y Paleopatología. Departamento de Bioantropología y Evolución. Facultad de Humanidades y Artes, Universidad Nacional de Rosario, Rosario, Argentina.

García Laborde, P., Suby, J. A., Guichón R. A. y Casali R. (2010) El antiguo cementerio de la Misión de Río Grande, Tierra del Fuego. Primeros resultados sobre patologías nutricionales-metabólicas e infecciosas. Revista Argentina de Antropología Biológica, 12, 57-69.

González, M. E. (2007). Estudios de interés tafonómico en los restos óseos humanos de la laguna Tres Reyes1 (Partido de Adolfo Gonzales Chaves). Intersecciones en Antropología, 8, 215-233.

Gordon, C. G. y Buikstra, J.E. (1981). Soil pH, bone preservation, and sampling bias at mortuary sites. American Antiquity, 46 (3), 566-571.

Guichón, R. A. (1994). Antropología física de Tierra del Fuego. Caracterización biológica de las poblaciones prehispánicas (Tesis doctoral). Facultad de Filosofía y Letras, Universidad de Buenos Aires, Buenos Aires.

Guichón, R. A. y Suby, J. A. (2006). La colección del Museo de Historia Natural de Londres correspondiente a restos óseos humanos de Patagonia Austral. Magallania, 34(2), 47-56. doi: 10.4067/S0718-22442006000200005

Guichón, R. A. y Suby, J. A. (2011). Estudio bioarqueológico de los restos óseos humanos recuperados por Anne Chapman en Caleta Falsa, Tierra del Fuego. Magallania, 39(1), 163-177. doi: 10.4067/S071822442011000100010

Guichón, R. A., Barberena, R., Borrero, L. A. (2001). ¿Dónde y cómo aparecen los restos óseos humanos en $\mathrm{Pa}$ tagonia Austral? Anales del Instituto de la Patagonia, 29, 103-118.

Guichón, R. A., Suby, J. A., Casali, R. y Fugassa, M.H. (2006) Health at the time of native-european contact in Southern Patagonia. First steps, results and prospects. Memorias do Instituto Oswaldo Cruz, 101 (Suppl. II), 97-105. doi: 10.1590/S0074-02762006001000016

Gusinde M. [(1931) 1982]a. Los indios de Tierra del Fuego. Los Selk'nam. Buenos Aires, Argentina: Centro Argentino de Etnología Americana, CONICET.

Gusinde M. [(1931) 1982]b. Los indios de Tierra del Fuego. Los Yamana. Buenos Aires, Argentina: Centro Argentino de Etnología Americana, CONICET.

Gutiérrez, M. A. (2004). Análisis tafonómicos en el área interserrana (Provincia de Buenos Aires) (Tesis doctoral). Facultad de Ciencias Naturales y Museo, Universidad Nacional de La Plata, La Plata.

Hilton, R. C., Ball, J. y Benn, R. T. (1976). Vertebral endplate lesions (Schmorl's nodes) in the dorsolumbar spine. Annals of the rheumatic diseases, 35 (2), 127-132.

Isçan, M. Y., Loth, S. R., y Wright, R.K. (1984). Metamorphosis at the sternal rib end: a new method to es- timate age at death in white males. American Journal of Physical Anthropology, 65,147-156. doi: 10.1002/ ajpa.1330650206

Jiménez-Brobeil, S. A., Al Oumaoui, I. A. y du Souich, P. (2010). Some types of vertebral pathologies in the Argar culture (Bronze age, SE Spain). International Journal of Osteoarchaeology, 20 (1), 36-46. doi: 10.1002/ oa. 1003

Jiménez-Brobeil, S., Roca-Rodríguez, M., Al Oumaoui, I y du Souich, P. (2012). Vertebral pathologies and related activity patterns in two mediaeval populations from Spain. Collegium antropologicum, 36 (3), 1019-1025.

Jurmain, R. D. y Kilgore, L. (1995). Skeletal evidence of osteoarthritis: a palaeopathological perspective. Annals of the Rheumatic Dissease, 54, 443-450.

Knüsel, C. J., Göggel, S. y Lucy, D. (1997). Comparative degenerative joint disease of the vertebral column in the Medieval monastic cemetery of the Gilbertine Priory of St. Andrew, Fishergate, York, England. American Journal of Physical Anthropology, 103 (4), 481-495. doi: 10.1002/(SICI)1096-8644(199708)103:4<481::AIDAJPA6>3.0.CO;2-Q

Kyere, K. A., Than, K. A. D., Anthony, C. W., Rahman, S. U., Valdivia-Valdivia, J. M., La Marca, F. y Park, P. (2012). Schmörl's nodes. European Spine Journal, 21: 2115-2121. doi: 10.1007/s00586-012-2325-9

Lalueza, C A. 1995. Recuperación de DNA mitocondrial y caracterización de variabilidad en poblaciones antiguas (Tesis doctoral). Departamento de Biología, Facultad de Ciencias, Universidad de Barcelona, Barcelona.

L'Heureux, G. L. y Amorosi, T. (2009). En entierro 2 del sitio Cañadón Leona 5 (Región de Magallanes, Chile). Viejos huesos, nuevos datos. Magallania, 37 (2), 41-55. doi: 10.4067/S0718-22442009000200003

L'Heureux, G. L., y Amorosi, T. (2010). El entierro del sitio Cerro Sota (Magallanes, Chile) A más de setenta años de su excavación. Magallania, 38 (2), 133-149. doi: 10.4067/S0718-22442010000200009

L'Hereux, G. y Barberena, R. (2008). Evidencias bioarqueológicas en Patagonia meridional: el sitio Orejas de Burro 1 (Pali Aike, provincia de Santa Cruz). Intersecciones en Antropología, 9, 11-24.

Ortner, D. J. (2003). Identification of pathological conditions in human skeletal remains. ( ${ }^{\mathrm{a}} \mathrm{ed}$.) San Diego, Estados Unidos: Elsevier.

Martucci, M. (2016). Heterogeneidad espacial en la Misión Salesiana Nuestra Señora de la Candelaria: Expresión de la identidad étnica Selk'nam durante el proceso de contacto interétnico (Rio Grande, Tierra del Fuego) (Tesis doctoral). Facultad de Ciencias Sociales, Universidad Nacional del Centro de la Provincia de Buenos Aires, Olavarría.

Novak, M., y Šlaus, M. (2011). Vertebral pathologies in two early modern period (16th-19th century) populations from Croatia. American Journal of Physical Anthropology, 145 (2), 270-281. doi: 10.1002/ajpa.21491

Pálfi, G. Y., Dutour, O., Berato, J. y Marcsik, A. (1994). Paleopathologie comparee de l'arthrose vertebrale dans plusiers series gallo-romaines et une serie hongroise. Paleobios, 10 (1-2-3), 67-80.

Plomp, K. A., Roberts, C. A. y Viðarsdóttir US. (2012) Vertebral Morphology Influences the Development of Schmörl's Nodes in the Lower Thoracic Vertebrae. American Journal of Physical Anthropology, 149, 572582.

Real Academia Nacional de Medicina -RANM- (2011). Diccionario de términos médicos. Madrid, España: Panamericana. 
Rascón, J., Cambra-Moo, O., Pimentel, G., González, A., y Campo, M. (2011). Influencia del estado de preservación de los restos óseos en el diagnóstico paleopatológico. En A. González, O. Cambra-Moo, J. Rascón, M. Campo, M. M. Robledo, y M. E. Labajo (Eds.), Actas del X Congreso Nacional de Paleopatología (pp. 4550). Universidad Autónoma de Madrid, Universidad Complutense de Madrid, Madrid, España: Sociedad Española de Paleopatología.

Rodríguez, W. C. y Bass, W. M. (1985) Decomposition of buried bodies and methods that may aid in their location. Journal of Forensic Science, 30 (3), 836-852.

Rogers, J. y Waldron, T. (1995). A Field Guide to Joint Disease in Archaeology. West Sussex, Estados Unidos: John Wiley \& Sons.

Rojas-Sepúlveda, C., Ardagna, Y., y Dutour, O. (2008). Paleoepidemiology of vertebral degenerative disease in a pre-Columbian Muisca Series from Colombia. American Journal of Physical Anthropology, 135 (4), 416430. doi: 10.1002/ajpa.20762

Santiago, F., Salemme, M., Suby, J. A. y Guichón, R.A. (2011). Restos óseos humanos en el norte de Tierra del Fuego. Aspectos contextuales, dietarios y paleopatológicos. Intersecciones en Antropología, 12, 147-162.

Schmörl, G. y Junghanns, H. (1959). The human spine in health and disease. New York, Estados Unidos: Grune \& Stratton.

Séguy, I. y Buchet, L. (2011). Manuel de paléodémographie. París, Francia: INED.

Suby, J. A., (2014). Nódulos de Schmörl en restos humanos arqueológicos de Patagonia Austral. Magallania, 42 (1), 135-147. doi: 10.4067/S0718-22442014000100008

Suby, J. A.y Guichón, R. A. (2010). Los restos óseos humanos de la colección de la Misión Salesiana "La Candelaria” (Río Grande, Argentina). Magallania, 38(2), 23-40. doi: $10.4067 / \mathrm{S} 0718-22442010000200010$

Suby, J. A., Guichón, R. A. y Senatore, M. X. (2009a). Los restos óseos humanos de Nombre de Jesús, evidencias de la salud en el primer asentamiento europeo en Patagonia Austral. Magallania, 37 (2), 23-40. doi: 10.4067/ S0718-22442009000200002

Suby, J. A., Guichón, R. A. y Zangrando, A. F. (2009b). El registro biológico humano de la costa meridional de Santa Cruz. Revista Argentina de Antropología Biológica, 11 (1), 109-124.

Suby, J. A., Santiago, F. y Salemme, M. (2008). Análisis paleopatológico de los restos humano sdel sitio Puerto Pescador 1 (Tierra del Fuego). Magallania, 36 (1), 5364. doi: $10.4067 / \mathrm{S} 0718-22442008000100005$

Suby, J. A., Zangrando, A. F. y Piana, E. (2011). Exploraciones osteológicas de la salud de las poblaciones humanas del Canal Beagle. Relaciones de la Sociedad Argentina de Antropología Biológica, XXXVI, 249-270.

Tibbet, M. y Carter, D. O. (2009). Research in forensic taphonomy: a soil-based perspective. Cadaver decompostion in terrestrial ecosystems. En K. Ritz, L. Dawson, D. Miller (Eds.), Criminal and Environmental Soil Forensics (pp. 317-332). Berlín, Alemania: Springer.

Todd, T. W. (1921a). Age changes in the pubic bone I: the male white pubis. American Journal of Physical Anthropology, 3, 285-334.

Todd, T. W. (1921b). Age changes in the pubic bone III: the pubis of the white female. American Journal of Physical Anthropology, 4, 1-70.

Üstündağ, H. (2009). Schmörl's nodes in a post-Medieval skeletal sample from Klostermarienberg, Austria. International Journal of Osteoarchaeology, 19 (6), 695-710. doi: 10.1002/oa.993

Van der Merwe, A E., Işcan, M. Y. y L'Abbè, E. N. (2006). The Pattern of Vertebral Osteophyte Development in a South African Population. International Journal of Osteoarchaeology, 16 (5), 459-464. doi: 10.1002/oa.841

Waldron, T. (1987). The relative survival of the human skeleton: implications for paleopathology. In A. Boddington, A. N. Gardland, R. C. Janaway (Eds.), Death, Decay and Reconstruction: Approaches to Archaeology and Forensic Science (Pp. 55-65). Manchester, Inglaterra: Manchester University Press.

Waldron, T. (1991). The prevalence of, and the Relationship Between Some Spinal Diseases in a Human Skeletal Population from London. International Journal of Osteoarchaeology, 1 (2), 103-110. doi: 10.1002/ oa.1390010206

Weiss, E. y Jurmain, R. (2007). Osteoarthritis revised: a contemporary review of etiology. International Journal of Osteoarchaeology, 17, 437-450. doi: http://dx.doi. org/10.1002/oa.889

Williams, F. M. K., Manek, N. J., Sambrook, P. N., Spector, T. D., y MacGregor, A.J. (2007). Schmörl's Nodes: common, highly heritable, and related to lumbar disc disease. Arthritis Care Research, 57 (5), 855-860. doi: 10.1002/art.22789 